\title{
Performance Evaluation of Switched Reluctance Motor in PV-fed Water Pump System with Different Controllers
}

\author{
Dr. M. Lakshmi Swarupa ${ }^{1}$ and R. Naveena Bhargavi ${ }^{2}$ \\ ${ }^{1}$ Professor, CVR College of Engineering/EEE Department., Hyderabad, India \\ swarupamalladi@gmail.com \\ ${ }^{2}$ Assoc. Professor,CVR College of Engineering/EEE Department., Hyderabad, India \\ bhargavi.rn5@gmail.com
}

\begin{abstract}
The agricultural motors need a more precise control and simple operation to have wet fields and better irrigation systems. The PV driven SRM is considered in this paper because, the robust operation and versatile speed control methods are available for this motor. The closed loop control of the motor is also tested, and a comparative analysis has been done for various controllers applied to SRM and the performance characteristics have been analyzed. The results obtained in the PID controller, Fuzzy logic Controller, SMC controller and the hybrid Fuzzy neural controller, the closed loop control are compared to the open loop control.
\end{abstract}

Index Terms: Switched Reluctance motor (SRM), Solar PV, PID controller, fuzzy controller fuzzy-neural controller, SMC controller, agricultural pumps.

\section{INTRODUCTION}

Our nation being predominantly agriculture based and irrigation centric, advancement of technology in this area will have a vast impact on the overall production of the Crop and the amount of water utilized for harvesting. Depending on the location of the field and the ground water availability, Water has to be provided as a supplement for proper growth of the plants in most of the cases [1]. Farmers make use of electric motor pumps to bring water from deep underground onto the surface. For many decades, induction motors are being used extensively for this purpose. With the advent of new machines, there are many efficient Motors available to use for irrigation. Switched reluctance Motors can deliver high torque, which can lift water and pump to the fields.

The construction of SRM is rugged and considered to be simple in construction. The cost is less and the reliability on the performance characteristics is high. The control part of the motor needs some switching techniques to be incorporated and there is a scope to develop new methods of control mechanisms. The sensor less control technique is more predominant. Hence it has been considered in the present paper.
Several control methods are available to minimize the ripple in torque of the motor, such as designing an optimal magnetic circuit and current control techniques. Based on the modelling of the machine, it can be seen that the torque control is different to the traditional methods used and has a range of control techniques and certain assumptions are made regarding the parameters considered for SRM.

The main power conversion is done from the reluctance power available in the motor to a useful mechanical using the salient pole construction. The lack of windings and magnets on the rotor makes it more rugged and simple in construction. The cost of this motor is less compared to the traditional squirrel cage induction motors, and the maintenance different Pulse Width Modulation techniques can be applied and obtain the required torque characteristics from the motor. The power drawn by this motor must come from the regional power distribution centers. But reliability of the power is very less in rural areas of the country. Hence there is a need of a standalone power supply.

The solar Photo Voltaic based power generation has been a boom to the agricultural sector and is being extensively used for water pumping. The problem is that the nature of power supply must meet the demands of input characteristics of SRM. The DC power developed must convert to AC using an inverter circuit and fed to SRM, The PV panel shall be mounted in such a way that the shadow of panel does not disrupt solar rays falling on the panel. The power generated is directly used by the motor instead of having a storage equipment.

In this paper, different control techniques are employed, and they are tested on the SRM to understand the performance characteristics. The paper is organized as follows: Section -2 deals with the mathematical modelling of SRM. The various technique used to control the performance of the parameters are presented in section -3 . Different controllers are also tested in the system, which are presented in section -4 . The MATLAB Simulink results are presented in section -5 , followed by conclusion and references used. 


\section{Modelling Of Switched Reluctance Motor}

The output of SRM which we are concerned here is the instantaneous torque, given in equation

$$
T_{i}=\frac{\delta W^{1}}{\delta A}
$$

where W1 is the co-energy defined in equation 2.

$W^{1}=\int_{0}^{i} \varphi \cdot d i$

The relationship between the flux linkage and the current at the instant rotor position $\vartheta$ is a straight line whose slope is the instantaneous inductance L. Thus,

$\psi=L * I$

and

$W^{1}=\frac{1}{2} L i^{2}$

Therefore, the torque is given by equation 5 .

$T=\frac{1}{2} i^{2} \frac{d L}{d \theta}$

The voltage equation is integrated in the form and is given as

$$
\varphi=\int(v-r i) d t
$$

\section{Control Algorithms}

\section{A. PID controller}

The Proportional Integral and Derivative control is a traditional way of driving the system towards a target setpoint. In this paper, we are using the PID controller to make the motor operate at desired torque and speed values at given point of time. This is generally a closed loop control of the system. Ziegler and Nichols method is used in the paper to find the optimum point of operation.

\section{B. Fuzzy Controller}

This technique to control the parameters of a system and optimize the operation of a system are considered here in the paper. The fuzzy membership function values are tuned by using neural network so that the output defuzzified value is in the expected range of the user. Here the PWM modulation index shall be optimally decided by the fuzzy logic controller.

\section{Sliding Mode Controller}

To control a nonlinear system, which changes the dynamics fast, a discontinuous control signal is needed. This methodology is adopted to slide along the behavior of the system randomly and to find out the best possible point to operate the system at. It has a feedback mechanism to check its position in space and has information about the next step to move. In this paper, SMC is applied and compared with the other methods.

\section{Simulation Models ANd Results}

\section{A. Model of SRM}

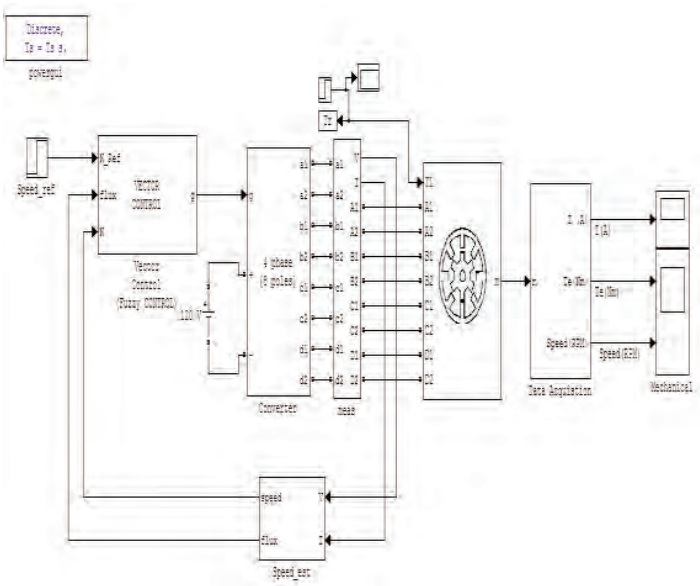

Figure 1. Simulation model of sensor less control

The SRM considered in the paper is a four phase 8 pole motor driven by a speed reference as a step function and also driven by a field excitation of $120 \mathrm{~V}$. The speed feedback is taken and vector-based control is implemented to have a sensor less control.

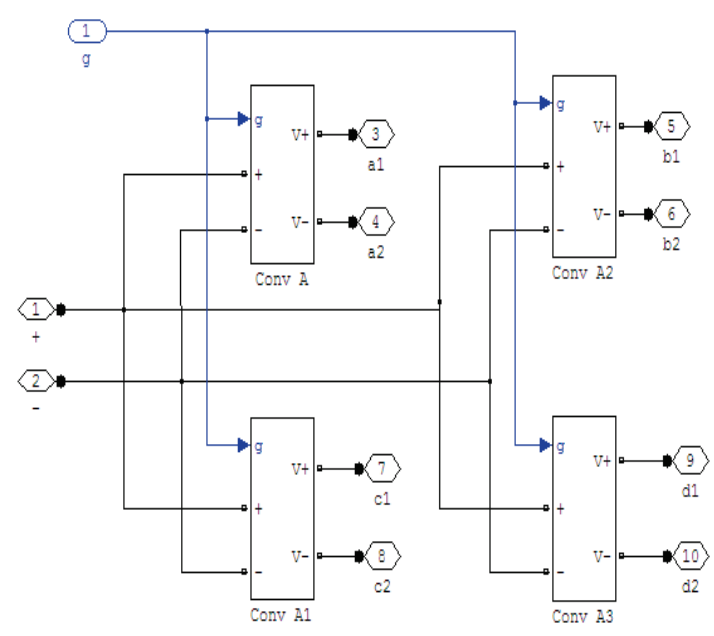

Figure 2. Converter control 
The converter used in the simulation is shown in figure 2.

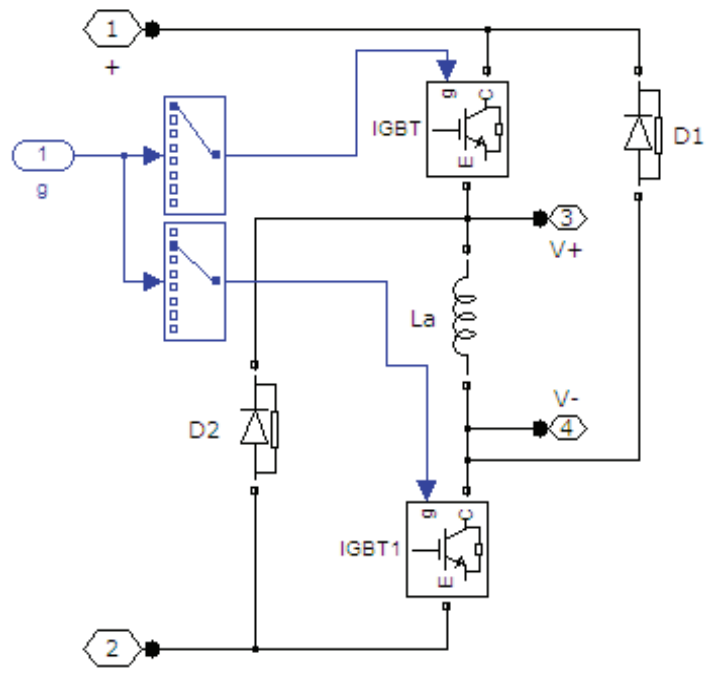

Figure 3. Subsystem of Bridge Rectifier

Figure 3 shows the circuit used for Bridge rectifier operation with IGBT as switches. A multi-port switch is connected to the gate terminals to provide specific outputs at specific points of rotations of shaft of motor.
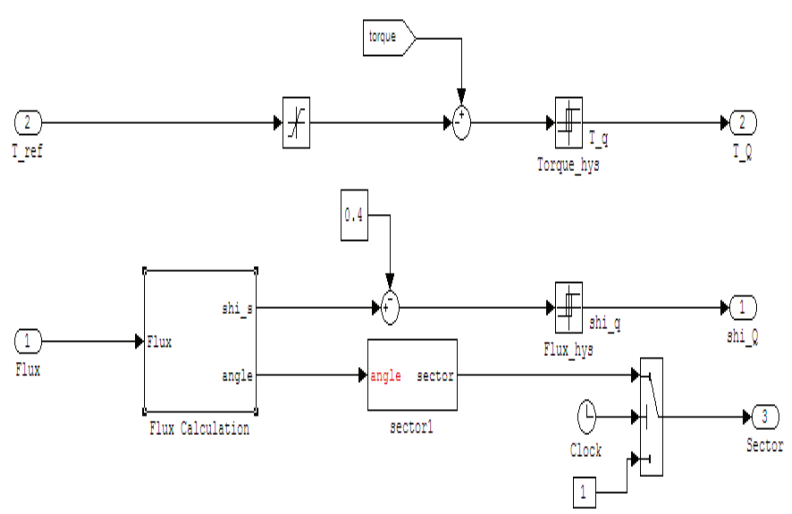

Figure 4. Subsystem of Mathematical Equations in Terms of Flux and Speed

The flux calculation along with torque of the motor helps in understanding the $\mathrm{Q}$ component of the torque and 'shi'. This is shown in figure 4. Figure 5 shows the flux equations to find out the angle of rotation of the shaft. This is expessed in polar format.

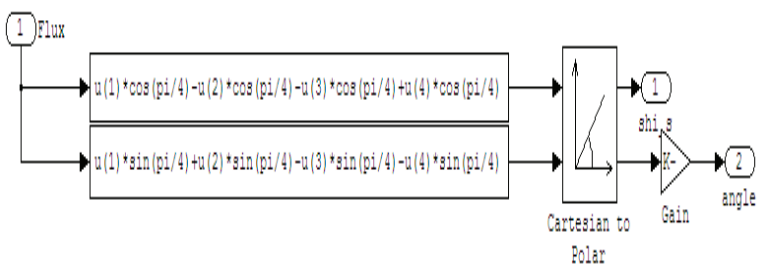

Figure 5. Equations of Flux in Polar (Angle) notation

\section{B. Without controller}

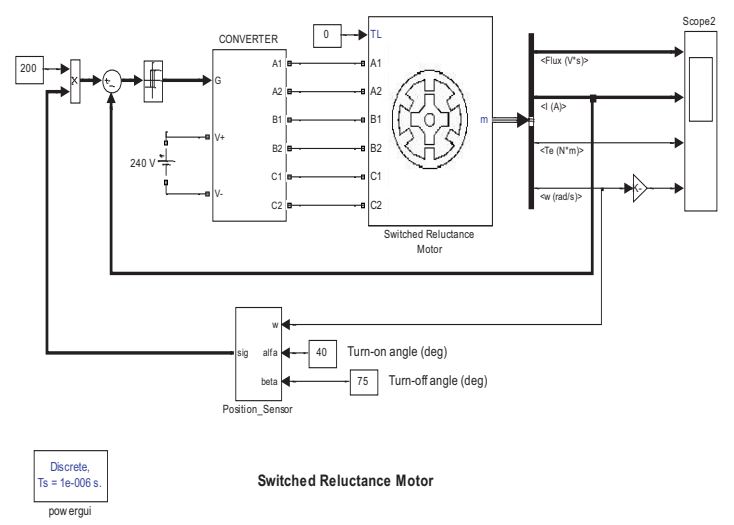

Figure 6. Simulation Model without Controller

The SRM considered in the paper without the feedback controller is shown in figure 6 .

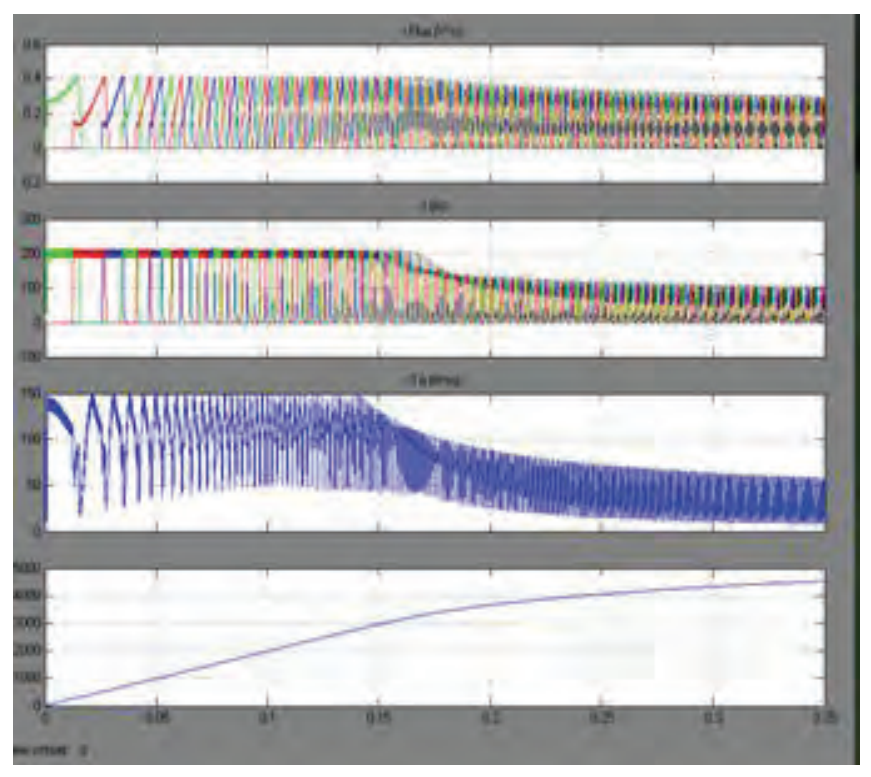

Figure 7. Flux (Wb), Current (Amps), Torque (N-M), Speed (Rpm) Versus Time (Secs) for NO Controller

Figure 7 shows that the speed of the motor is increasing significantly but is not controlled for settling at a finite value. After $0.15 \mathrm{~s}$, there is a certain shift in the response of torque and current.

\section{With PID controller}

The error obtained due to uncontrolled operation can be overcome by introducing another controller called PID controller. The system considered is shown in figure 8 , and the results obtained are shown in figure 9 respectively. 


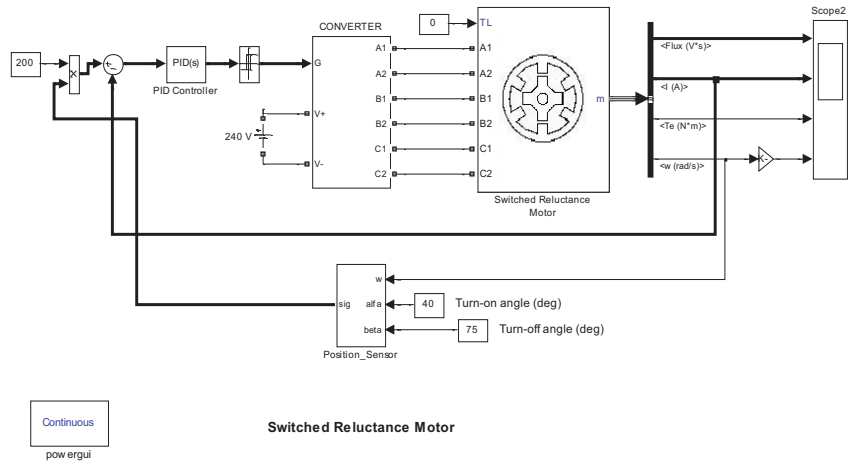

Figure 8. Simulation Model with PID Controller

The system is now tested with a fuzzy logic controller to control the speed and torque of the motor. The sample of fuzzy inference rules are shown in figure 10. There are three input and three outputs considered in the fuzzy controller. The schematic of the same is shown in figure 11.

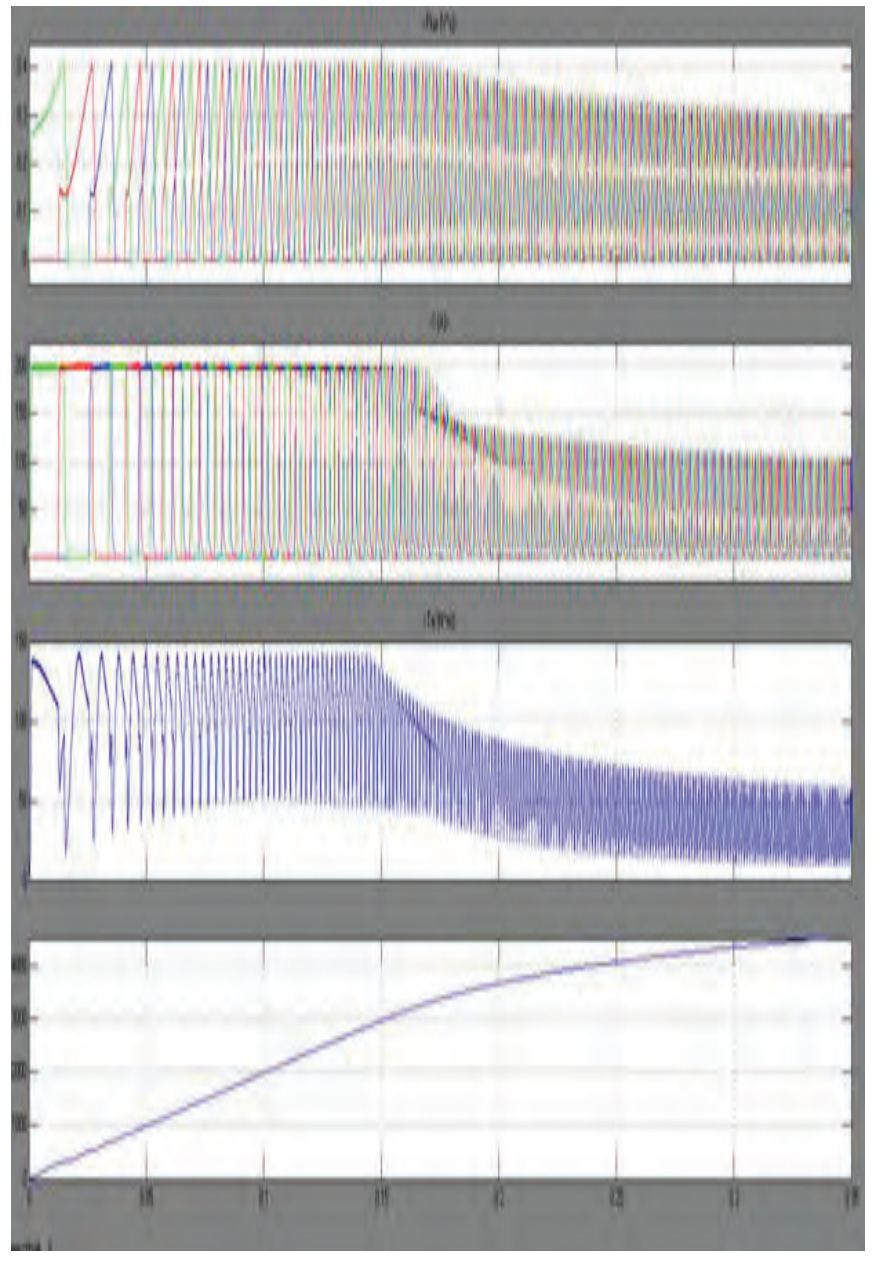

Figure 9. Flux (Wb), Current (Amps), Torque (N-M), Speed (Rpm) Versus Time (Secs) with PID Controller
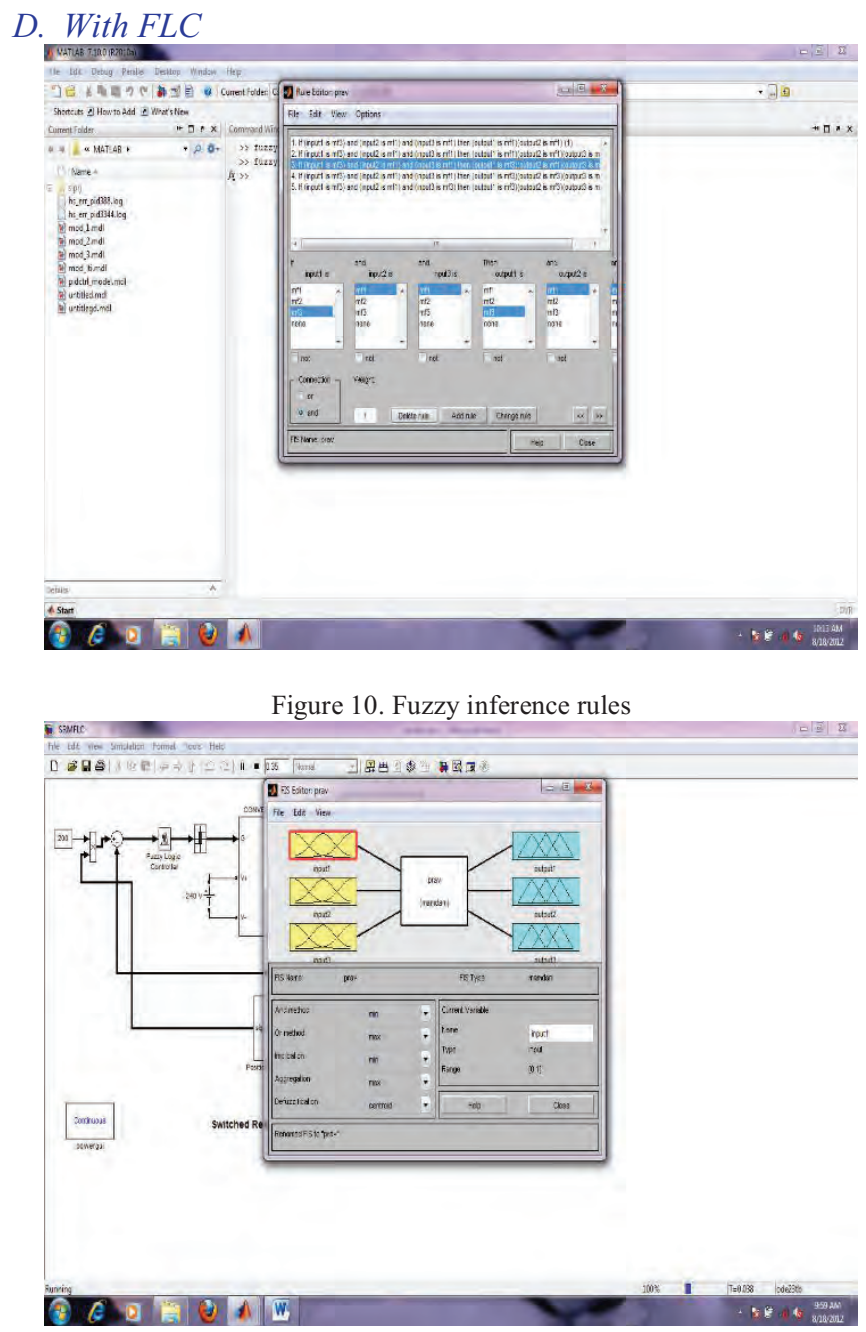

Figure 11. Fuzzy inference system rules and its implication

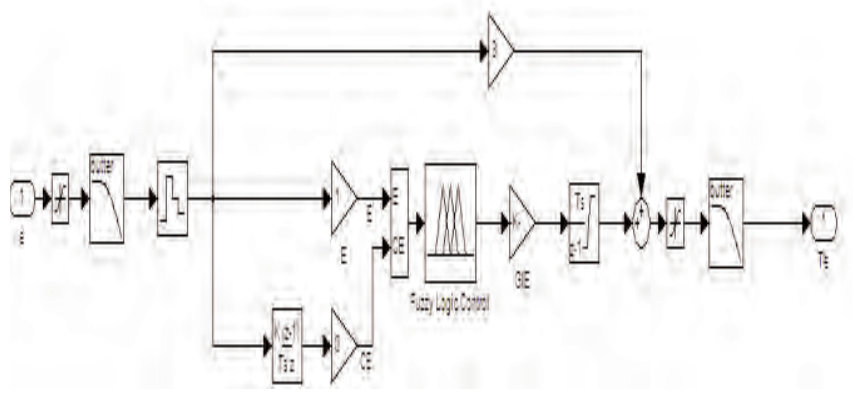

Figure 12. Subsystem of FLC Controller in SRM

Once the fuzzy rules are read, the controller is placed in the main system to give the control output to change the electrical torque as shown in figure 12. The data will be collected and presented in a subsystem of the simulation called data acquisition. This is shown in figure 13. The flux, current and 
speed parameters can be analysed in this block. The outputs obtained are shown in figures 14 and 15 respectively.

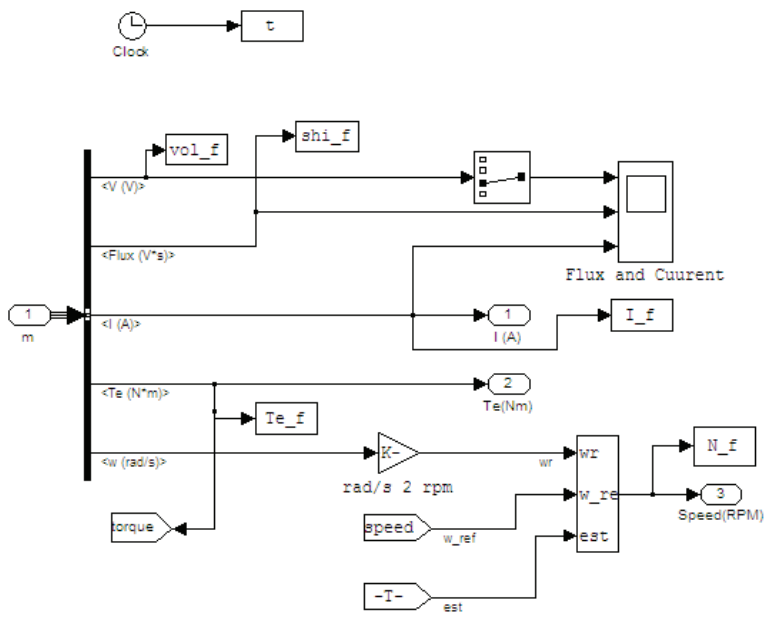

Figure 13. Subsystem of the data acquisition system

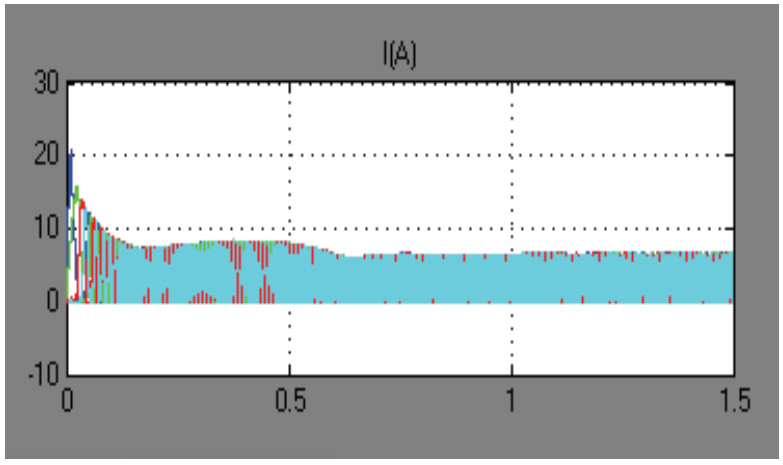

Figure 14. Current (Amps) Versus Time(secs)

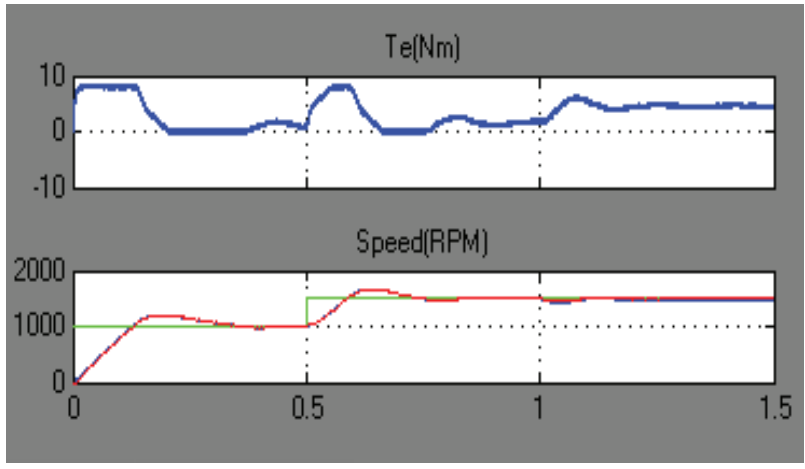

Figure 15. Torque (Nm) and Speed (rpm) Versus Time (secs)

\section{E. With $S M C$}

SMC controller is also used to check the efficiency of the motor to be controlled for speed and torque, as required by the load. Figure 16 shows the schematic and figure 17 shows the output waveforms of speed and torque. It can be observed that the controller is successful in controlling the torque.

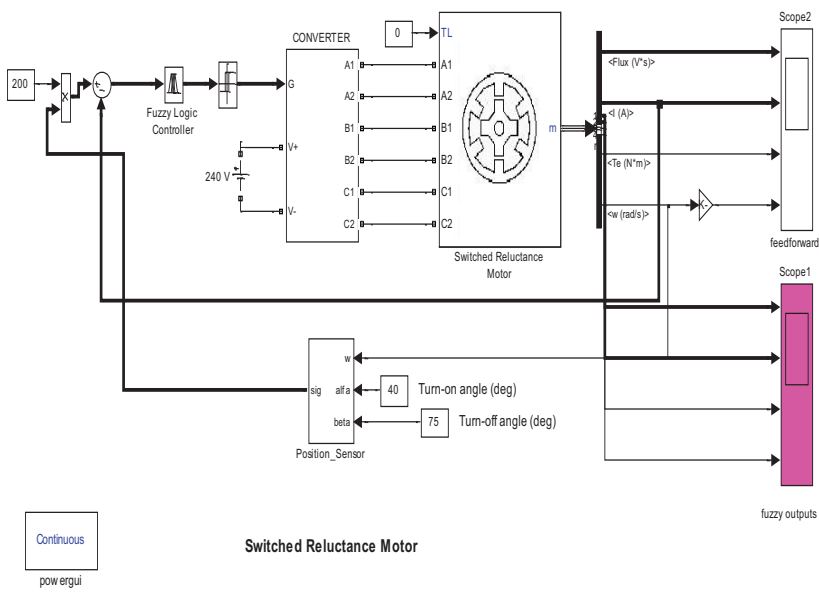

Figure 16. Simulation model with SMC controller

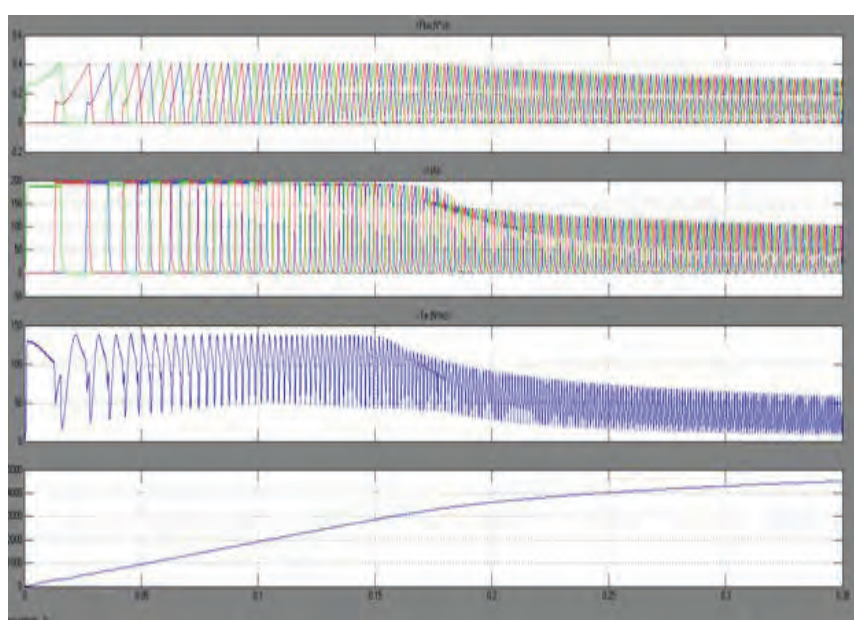

Figure 17. Flux (Wb), Current (Amps), Torque (N-M), Speed (Rpm) Versus Time (Secs) with SMC Controller

Figure 18 shows the filtering of the signal that is obtained by using the first order transfer function, that has been beneficial to analyses the signals.

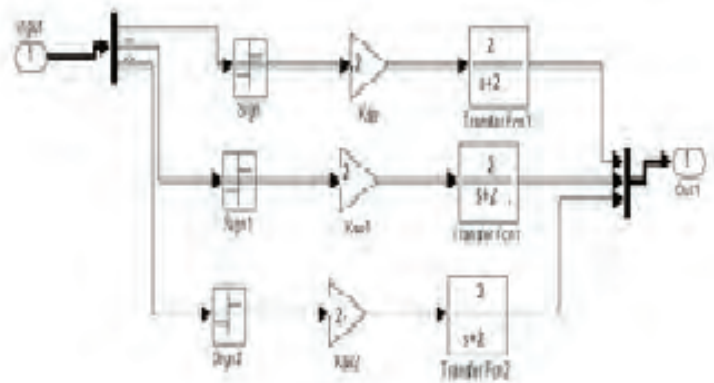

Figure 18. Filter circuit design 


\section{F. Technical Specifications}

Specifications: Phase number 4; Number of stator poles 8; $22.6^{\circ}$ pole arc; Number of rotor poles $6 ; 23.0^{\circ}$ pole arc; Maximum inductance $9.15 \mathrm{mH}$ (unsaturated); Minimum inductance $1.45 \mathrm{mH}$; Phase resistance $R=0.3 \Omega$; Moment of inertia $J=0.0027 \mathrm{Kg} / \mathrm{m}^{2}$; Friction $f=0,0067 \mathrm{Nm} / \mathrm{s}$; Inverter voltage $V=100 \mathrm{~V}$. Speed reference: $1500 \mathrm{rpm}$

TABLE I.

COMPARISON TABLE OF ZETA CONVERTER OF SRM WITH DIFFERENT CONTROLLERS

\begin{tabular}{|c|c|c|c|c|c|c|l|}
\hline \multirow{2}{*}{$\begin{array}{c}\text { Type of } \\
\text { controller }\end{array}$} & \begin{tabular}{c}
$|c|$ \\
$\mathbf{I}$ \\
\cline { 2 - 7 }
\end{tabular} & $\begin{array}{c}\mathrm{N} \\
(\mathrm{rpm})\end{array}$ & $\begin{array}{c}\mathrm{T} \\
(\mathrm{N}-\mathrm{m})\end{array}$ & $\begin{array}{c}\mathrm{I} \\
(\mathrm{A})\end{array}$ & $\begin{array}{c}\mathrm{N} \\
(\mathrm{rpm})\end{array}$ & $\begin{array}{c}\mathrm{T} \\
(\mathrm{N}-\mathrm{m})\end{array}$ & $\begin{array}{l}\text { Inductance } \\
(\mathrm{mH})\end{array}$ \\
\hline $\begin{array}{c}\text { No } \\
\text { controller }\end{array}$ & 0.5 & 1.5 & 50 & 0.48 & 1.4 & 548 & 0.99 \\
\hline $\begin{array}{c}\text { PID } \\
\text { Controller }\end{array}$ & 0.45 & 1.3 & 45 & 0.425 & 1.25 & 42 & 1.42 \\
\hline $\begin{array}{c}\text { FLC } \\
\text { Controller }\end{array}$ & 0.456 & 1.2 & 52 & 0.424 & 1.21 & 47 & 1.245 \\
\hline $\begin{array}{c}\text { SMC } \\
\text { Controller }\end{array}$ & 0.215 & 0.9 & 35 & 0.201 & 0.99 & 31.2 & 1.016 \\
\hline
\end{tabular}

\section{G. Analysis}

The waveform of the circulating current in steady state is shown in the Figure.17. Note that this current cannot be directly measured as such and it has to be calculated. Also note that it is not perfect DC because of the inductive energy storage in the windings. The circulating current contains a ripple of mainly triple harmonics that repeats every 120 . The performance of the SRM is mainly manifested in its speed and torque characteristics. So, the current, speed and torque error should be almost zero, and to neglect the error, controllers are used.

In switched reluctance motors (SRMs) yields minimum and maximum points in the inductance profile. Minimum and maximum inductances directly affect energy conversion capabilities of a given design. Estimating the maximum inductance is a relatively simple process, even if MW drop in the magnetic steel is not: ignored. However, minimum inductance estimation is much more difficult task due to the uncertain path of airgap magnetic field which is dominated by fringing between rotor and stator poles. A new approach is proposed in this paper to estimate minimum inductance (Lmin) of SRM. The conventional phase current-torque equation for SRM is a function of slope of inductance with respect to rotor position. Hence, an accurate value of the inductance profile is essential to compute suitable phase current, which flows into motor phase winding and produces desired torque with minimum torque ripple.
Model Predictive Control (MPC) can directly manipulate the switches of the DC-link power converter. The results of applying the sliding mode controller to a SRM give best performances and high robustness than those obtained by the application of a conventional controller (PI). The simulation results show that the proposed controller is superior to conventional controller in robustness and in tracking precision. The overshoot is less important in the case of the sliding regulator, with a best response time without increasing the overshoot. The simulation study clearly indicates the superior performance of sliding control because it is inherently adaptive in nature. It appears from the response properties that it has a high performance in presence of the plant parameters uncertain and load disturbances. It is used to control system with unknown model. The control of speed by SMC gives fast dynamic response without overshoot and zero steady-state error.

\section{Conclusions}

The agricultural motors need a more precise control and simple operation to have wet fields and better irrigation systems. The PV driven SRM is hence the best combination of a motor pump, because the robust operation and speed controls are available. A comparative analysis has been done for various controllers applied to SRM and the performance characteristics have been analyzed. It is found that out of the PID controller, Fuzzy logic Controller, SMC controller and the hybrid Fuzzy - neural controller, the closed loop control has many advantages compared to the open loop control.

\section{REFERENCES}

[1] Krishnan, R.: Switched Reluctance Motor Drivers, Modeling, Simulation, Analysis, Design, and Applications, CRC Press, Boca Rraton, London, 2001.

[2] KRISHNAN, R.: Switched Reluctance Motor Drivers, Modeling, Prentic-Hall, USA, 1994.

[3] Badari Mahayana P, Sanjeeva Reddy BR, Prasad M, Sanjay D. Design \& simulation of solar DC pump in Simulink. IEEE Trans 2013;978 (1):4673-6150.

[4] Ould-Amrouche S, Rekioua D, Hamidat A. Modelling photovoltaic water pumping systems and evaluation of their $\mathrm{CO} 2$ emissions mitigation potential. Appl Energy 2010; 87:3451-9.

[5] Maurya VN, Diwinder Kaur A, Maurya AK, Gautam RA. Numerical simulation and design parameters in solar photovoltaic water pumping systems. Am J Eng Technol 2013; 1:01-9.

[6] Biji G. Modelling and simulation of PV based pumping system for maximum efficiency. IEEE Trans 2012.

[7] Jafar M. A model for small-scale photovoltaic solar water pumping. Renew Energy 2000; 19:85-90.

[8] Flores C, Poza F, Narvarte L. A tool to widen the possibilities of PV pumping simulation. Int J Sustain Energy 2012; 31:73-84. 
[9] Velvizhi J, Subramanian DP. Performance enhancement of PV based water pumping system. Int J Innov Technol Explor Eng 2014;3(10):2278-3075.

[10] Wagdy R, Nourb MA. Optimum design of a photovoltaic powered pumping system. J Power Sources 1994;50:1-9.

[11] Argaw N. Optimization of photovoltaic water pumps coupled with an interfacing pulse width modulated dc/ac inverter power conditioning devices; 1994. p. 1165-8, (IEEE First WCPEC; December 5-9, 1994; Hawaii).

[12] Yahia B, Arab AH, Azoui B. Optimal sizing of photovoltaic pumping system with water tank storage using LPSP concept. Sol Energy 2011; 85:288-94.

[13] Kaldellis JK, Spyropoulos GC, Kavadias KA, Koronaki IP. Experimental validation of autonomous PV-based water pumping system optimum sizing. Renew Energy 2009; 34:1106-13.

[14] Zvonimir G, Margeta J. A model for optimal sizing of photovoltaic irrigation water pumping systems. Sol Energy 2007; 81:904-16.

[15] Hamidat A, Benyoucef B. Mathematic models of photovoltaic motor-pump systems. Renew Energy 2008; 33:933-42.

[16] Firatoglu Z, Yesilata B. New approaches on the optimization of directly coupled PV pumping systems. Sol Energy 2004; 77:81-93.

[17] Cuadros F, Rodriguez FL, Marcos A, Coello J. A procedure to size solar powered irrigation (photo irrigation) schemes. Sol Energy 2004; 76:465-73.

[18] J.M. Mcknion and H.E. Lemmon, Symbolic Computer and Al Yools for a Cotton Expert System, ASAE Paper No: 85-5520, St. Joseph, MI, 1985.

[19] J. Jones, Interfacing an Expert Diagnostic Tool to Real Time Data, ASAE Paper No. 85-5522, St, Joseph, MI, 1985.

[20] Hasbini, B.A., Buchleiter, G.W., and Duke, H.R. (1991) Expert system for improved irrigation management. Proc. Int. Summer Meet. American Society of Agricultural Engineers, Albuquerque, New Mexico, June 23-26, 1-17. 